\title{
Internal Curing and Temperature Effect on Lightweight and Heat Insulated Mortar with Recycled Concrete Aggregate
}

\author{
S.T. YILDIRIM ${ }^{a, *}$, K. BAYNAL ${ }^{b, c}$ AND O. FIDAN ${ }^{a}$ \\ ${ }^{a}$ Kocaeli University, Engineering Faculty, Department of Civil Engineering, 41380 Kocaeli, Turkey \\ ${ }^{b}$ Kocaeli University, Engineering Faculty, Department of Industrial Engineering, 41380 Kocaeli, Turkey \\ ${ }^{c}$ Kyrgyz-Turkish Manas Univ., Fac. of Economics and Manag., Dep. of Manag., Bishkek, Kyrgyzstan \\ One of the best methods of waste recycling in the construction sector is to employ it in concrete or mortar \\ preparation. In this study, recycled concrete aggregate and bottom ash were used as aggregates in the mortar. \\ Additionaly, expanded perlite which is a material providing lightness, heat insulation and fire resistance, was \\ also used as aggregate. Calcium aluminate cement was preferred as binder to improve fire resistance. Results \\ were obtained and evaluated in terms of flexural and compressive strength, dry unit weight, water absorption, \\ capillarity, thermal conductivity, thermal resistance and cost by following a Taguchi method to internal curing, \\ cement quantity and aggregate ratio as parameters.
}

DOI: 10.12693/APhysPolA.135.865

PACS/topics: mortar, recycled concrete aggregates, bottom ash, expanded perlite, calcium aluminate cement, Taguchi method

\section{Introduction}

The most frequently used material in the construction sector is mortar. The mortar is an advantageous material to produce concrete, plaster and some wall materials. The obtained insulation materials, different from concrete, is sought for lightness and insulation properties [1]. Moreover, fireproofing is also a desirable feature in new types of building materials [2]. For this purpose, basic mortar binders such as cement and lime can be used as well as products such as generalized perlite and thermal power plant waste [3]. The expanded perlite $(\mathrm{P})$ is a favorable material in terms of water retention, a negative material in terms of water absorption, capillary, permeability and mechanical properties [4]. Especially in terms of the reduction of thermal conductivity, perlite is a material which is preferably used and can significantly reduce the value of thermal conductivity by reducing unit weight of mortar [5-7]. In addition, perlite is one of the preferred materials in making refractory material with calcium alumina cement (CAC), known as fireproof [8]. Bottom ash (BA), which is the waste from thermal power plants of still not sufficiently widespread use, is the material that can enhance heat insulation in mortars thanks to its lightweightness and hollow structure [9]. This material is harmless for health and is used as replacement to cement or aggregate in mortar. Although it has a negative effect on the strength, it can provide the economy in term of sustainability and recycling [10].

*corresponding author; e-mail: styildirim@kocaeli.edu.tr
In experimental studies, it is possible to take advantage of the Taguchi method in order to reduce specimen numbers and achieve more precise, detailed and optimal results with fewer specimens. The method is based on the principle of minimal experimentation to keep the costs as low as possible. This method is effective in improving the quality of the products and provides better results with less experimentation [11, 12].

Besides the waste products such as recycled concrete aggregate (RA) and bottom ash, a natural, light and insulating aggregates, such as perlite, are also utilized in the study. All of these materials are strongly waterabsorbing materials, so the internal curing (IC) method is utilized. Furthermore, these aggregate products, which are highly fireproof, have been developed as a binder by utilizing calcium alumina cement as a component of the composition. Different types of experimental castings were made according to the test pattern that was created according to the Taguchi method; physical and mechanical experiments, flexural and compressive strength, dry unit weight, water absorption, capillary water absorption, temperature resistance, heat insulation tests have been completed and cost calculated.

\section{Experimental design}

In the experimental study, calcium aluminate cement was used as a binder, and expanded perlite, bottom ash and recycled concrete aggregate as aggregate and filler material.

Some of the physical, chemical and mechanical properties of applied CAC, BA and P are given in Table I. The density of RCA was found as $2.4 \mathrm{~g} / \mathrm{cm}^{3}$. Water absorption of RCA, BA and $\mathrm{P}$ were $5.6 \%, 123 \%$ and $32.4 \%$, respectively. In Table II, granulometry of all aggregate 
materials and aggregate mixtures are given according to the rates used in the design of the Taguchi method (levels of parameter $\mathrm{C}$ ).

Table III shows the specified parameters and levels for Taguchi method. According to the Taguchi method for 3 parameters and 4 levels, the optimal result among the $4^{3}=64$ possible designs were limited to 16 types of designs. L16' pattern was used in the study (Table IV). The parameter 4 (D) was only used to detect decrease in the compressive strength with the temperature effect and is shown in the dark color in Table III and Table IV. Parameter 4 was not used in tests except for decrease in compressive strength (\%) and other test results were found based on 4 levels of the first 3 parameters in Table IV. The average values for all test results are shown in Table IV. All results except for the cost are given as average of three specimens.

Abundant water-absorbing materials; P, BA and RA were used as IC material in the first three levels of IC of the parameters (A), curing was not done in level 4 . The second parameter (B), the dosage of cement, was determined as 150, 175, 200 and $225 \mathrm{~kg}$ for $1 \mathrm{~m}^{3}$ mortar.
The aggregates used in the $\mathrm{C}$ parameter was volumetric in the mixture. According to this, each aggregate rate of the first 3 levels was considered to be 2 times the others and $\mathrm{P}, \mathrm{BA}$ and $\mathrm{RA}$ rates in the last level were taken as equal.

TABLE I

Chemical, physical and mechanical properties of cement, perlite and bottom ash.

\begin{tabular}{c|c|c|c}
\hline \hline Properties & \multicolumn{3}{|c}{ Materials } \\
\hline Chemical analysis & CAC & P & BA \\
\hline $\mathrm{SiO}$ & 3.60 & 71.3 & 57.76 \\
$\mathrm{Al}_{2} \mathrm{O}_{3}$ & 39.8 & 14.7 & 23.32 \\
$\mathrm{Fe}_{2} \mathrm{O}_{3}$ & 17.05 & 0.43 & 7.52 \\
$\mathrm{CaO}$ & 36.2 & 1.20 & 2.06 \\
$\mathrm{MgO}$ & 0.65 & 0.56 & 1.72 \\
$\mathrm{SO}_{3}$ & 0.04 & - & 0.38 \\
$\mathrm{TiO}_{2}$ & - & - & 1.12 \\
$\mathrm{Na}_{2} \mathrm{O}$ & - & 6.10 & 0.64 \\
$\mathrm{~K}_{2} \mathrm{O}$ & - & 3.40 & 1.99 \\
loss on ignition & 0.30 & - & 3.16
\end{tabular}

The granulometry of aggregate materials and their mixtures.

TABLE II

\begin{tabular}{c|c|c|c|c|c|c|c}
\hline \hline Sieve size $[\mathrm{mm}]$ & RA & BA & P & 2P:1BA:1RA & 1P:2BA:1RA & 1P:1BA:2RA & 1P:1BA:1RA \\
\hline 8 & 100 & 100 & 100 & 100 & 100 & 100 & 100 \\
4 & 56 & 99 & 100 & 89 & 89 & 78 & 85 \\
2 & 30 & 97 & 71 & 67 & 54 & 40 & 48 \\
1 & 19 & 92 & 32 & 44 & 59 & 29 & 35 \\
0.5 & 11 & 76 & 18 & 31 & 45 & 16 & 19 \\
0.25 & 5 & 41 & 11 & 17 & 25 & 7 & 8 \\
0.15 & 5 & 11 & 8 & 8 & 9 & 2 & 2 \\
0.063 & 1 & 2 & 4 & 3 & 2 & 0 & 0
\end{tabular}

TABLE III

The specified parameters and levels for Taguchi method. A - Internal curing, B - Cement dosage $\left[\mathrm{kg} / \mathrm{m}^{3}\right]$, $\mathrm{C}$ - Aggregate ratio, $\mathrm{D}$ - Temperature $\left[{ }^{\circ} \mathrm{C}\right]$.

\begin{tabular}{c|c|c|c|c}
\hline \hline \multirow{2}{*}{ Parameters } & \multicolumn{4}{|c}{ Levels } \\
\cline { 2 - 5 } & 1 & 2 & 3 & 4 \\
\hline $\mathrm{A}$ & $\mathrm{P}$ & $\mathrm{BA}$ & $\mathrm{RA}$ & - \\
$\mathrm{B}$ & 150 & 175 & 200 & 225 \\
$\mathrm{C}$ & $2 \mathrm{P}: 1 \mathrm{BA}: 1 \mathrm{RA}$ & $1 \mathrm{P}: 2 \mathrm{BA}: 1 \mathrm{RA}$ & $1 \mathrm{P}: 1 \mathrm{BA}: 2 \mathrm{RA}$ & $1 \mathrm{P}: 1 \mathrm{BA}: 1 \mathrm{RA}$ \\
$\mathrm{D}$ & 20 & 300 & 600 & 900
\end{tabular}

D parameter shows the temperature levels of the furnace where the materials were exposed. Materials were in the room temperature in the first level and was not put into the furnace. At the other three levels, the materials were kept in the oven at a temperature of 300, 600 and $900^{\circ} \mathrm{C}$ for 6 hours. The furnace temperatures were increased to 300,600 and $900^{\circ} \mathrm{C}$ after 1,2 and 3 hours, respectively. After 6 hours of heating the specimens, the furnace was turned off. Then, the furnace lid was opened, and the specimens were kept until the cooling to the room temperature.
Flexural tests were carried out on prismatic specimens of $40 \times 40 \times 160 \mathrm{~mm}$. Cube compressive strength was measured on $40 \times 40 \times 40 \mathrm{~mm}$ section of the divided prism used in the flexural test. In order to find a decrease in compressive strength with temperature, compressive strength test was performed on the same type of $50 \times 50 \times 50 \mathrm{~mm}$ specimens before firing and after firing, and loss percentage of the strength was calculated.

After $40 \times 40 \times 160 \mathrm{~mm}$ prismatic specimens were kept in drying oven for 24 hours, their dry density were determined as by proportioning the weight to volume ratio of the sample. According to EN 1015-18 [13], the oven dry prismatic were cut into two equal parts $(40 \times 40 \times 80 \mathrm{~mm})$ and the cut-off surfaces were contacted with water to determine the capillary water absorption percentage after 90 minutes. Square plates with dimensions of $330 \times 330 \times 50 \mathrm{~mm}$ were subjected to thermal conductivity test according to EN 12664 [14] and thermal conductivity coefficients were calculated. Considering the costs of aggregate and cement materials, only $1 \mathrm{~m}^{3}$ cost analysis was performed on the materials. 
L16 ${ }^{\prime}$ experimental plan and results for Taguchi method.

TABLE IV

\begin{tabular}{|c|c|c|c|c|c|c|c|c|c|c|c|c|}
\hline \multirow[t]{2}{*}{ Experiment } & \multicolumn{4}{|c|}{$\begin{array}{c}\text { Parameters } \\
\text { and their levels }\end{array}$} & \multirow{2}{*}{$\begin{array}{c}\text { Compressive } \\
\text { strength } \\
{[\mathrm{MPa}]}\end{array}$} & \multirow{2}{*}{$\begin{array}{c}\text { Flexural } \\
\text { strength } \\
{[\mathrm{MPa}]}\end{array}$} & \multirow{2}{*}{$\begin{array}{c}\text { Decr. } \\
\text { of comp. Str. } \\
{[\%]}\end{array}$} & \multirow{2}{*}{$\begin{array}{c}\text { Dry unit } \\
\text { weigth } \\
{\left[\mathrm{g} / \mathrm{cm}^{3}\right]}\end{array}$} & \multirow{2}{*}{$\begin{array}{c}\text { Water } \\
\text { absorption } \\
{[\%]}\end{array}$} & \multirow{2}{*}{$\begin{array}{c}\text { Capillarity } \\
{[\%]}\end{array}$} & \multirow{2}{*}{$\begin{array}{l}\text { Thermal } \\
\text { conduct. } \\
{[\mathrm{W} / \mathrm{m} \cdot \mathrm{K}]}\end{array}$} & \multirow[t]{2}{*}{$\begin{array}{c}\text { Cost } \\
{\left[\text { Euro } / \mathrm{m}^{3}\right]}\end{array}$} \\
\hline & $\mathrm{A}$ & B & $\mathrm{C}$ & $\mathrm{D}$ & & & & & & & & \\
\hline 1 & 1 & 1 & 1 & 1 & 0.31 & 0.23 & 1.01 & 1.01 & 40.0 & 20.5 & 0.12 & 18.7 \\
\hline 2 & 1 & 2 & 2 & 2 & 0.44 & 0.12 & 1.06 & 1.06 & 36.7 & 17.3 & 0.13 & 12.9 \\
\hline 3 & 1 & 3 & 3 & 3 & 0.36 & 0.12 & 1.21 & 1.21 & 24.7 & 13.3 & 0.17 & 13.6 \\
\hline 4 & 1 & 4 & 4 & 4 & 0.68 & 0.20 & 1.20 & 1.20 & 30.6 & 24.0 & 0.16 & 16.5 \\
\hline 5 & 2 & 1 & 2 & 3 & 0.58 & 0.24 & 1.01 & 1.01 & 37.2 & 13.4 & 0.11 & 12.1 \\
\hline 6 & 2 & 2 & 1 & 4 & 0.63 & 0.21 & 0.82 & 0.82 & 46.3 & 11.9 & 0.16 & 19.4 \\
\hline 7 & 2 & 3 & 4 & 1 & 0.67 & 0.21 & 0.99 & 0.99 & 36.9 & 11.4 & 0.10 & 15.8 \\
\hline 8 & 2 & 4 & 3 & 2 & 0.75 & 0.25 & 1.23 & 1.23 & 29.6 & 11.9 & 0.12 & 14.4 \\
\hline 9 & 3 & 1 & 3 & 4 & 0.60 & 0.24 & 1.21 & 1.21 & 26.0 & 19.0 & 0.19 & 12.1 \\
\hline 10 & 3 & 2 & 4 & 3 & 0.49 & 0.23 & 0.97 & 0.97 & 38.8 & 30.2 & 0.14 & 15.0 \\
\hline 11 & 3 & 3 & 1 & 2 & 0.25 & 0.1 & 0.76 & 0.76 & 48.3 & 47.1 & 0.14 & 20.1 \\
\hline 12 & 3 & 4 & 2 & 1 & 0.47 & 0.12 & 0.89 & 0.89 & 43.1 & 34.9 & 0.15 & 14.4 \\
\hline 13 & 4 & 1 & 4 & 2 & 0.51 & 0.16 & 0.97 & 0.97 & 41.9 & 24.2 & 0.11 & 14.3 \\
\hline 14 & 4 & 2 & 3 & 1 & 0.74 & 0.23 & 1.28 & 1.28 & 25.5 & 13.7 & 0.12 & 12.8 \\
\hline 15 & 4 & 3 & 2 & 4 & 0.90 & 0.24 & 0.93 & 0.93 & 47.1 & 20.7 & 0.13 & 13.6 \\
\hline 16 & 4 & 4 & 1 & 3 & 1.16 & 0.33 & 0.99 & 0.99 & 39.0 & 23.2 & 0.11 & 20.7 \\
\hline
\end{tabular}

\section{Results and discussion}

While it is aimed to obtain high values of compressive strength and flexural strength results from experiments, it is required to avoid small values of results because unsignificant experiments are time-consuming and costly. S/N ratios were calculated for each experiment. According to the performance statistics calculated from the $\mathrm{S} / \mathrm{N}$ ratios, each experiment was evaluated and optimum levels and optimal values in these levels were found (Table V). The overall evaluation was made by taking averages of 8 different criteria with high $\mathrm{S} / \mathrm{N}$ ratios. Figure 1 gives the relationship between performance statistic parameters. It shows parameters and levels for $\mathrm{S} / \mathrm{N}$ ratio values of each experiment.

- Compressive strength. Composite mortar material with the highest amount of CAC $\left(225 \mathrm{~kg} / \mathrm{m}^{3}\right)$ without $\mathrm{IC}$, in which $\mathrm{BA}$ is used more as aggregate has emerged as the combination that will achieve the highest performance. A-IC parameter is dominant, followed by BCement dosage and C-Aggregate ratio, respectively. The increase in cement amount increases strength.

- Flexural strength. The specimens without IC, the CAC dosage of $150 \mathrm{~kg} / \mathrm{m}^{3}, 2 \mathrm{P}: 1 \mathrm{BA}: 1 \mathrm{RA}$ as aggregate ratio gave the highest result. A, C, and $\mathrm{B}$ have been effective on this feature, respectively.

- Decrease of compressive strength. The optional temperature parameter has played the most important role in the decrease of compressive strength. However, it was analyzed how the other three parameters change because the temperature parameter is only used for this test. IC condition, the cement dosage $\left(150 \mathrm{~kg} / \mathrm{m}^{3}\right)$ and the aggregate ratios (2P: 1BA: $1 \mathrm{RA})$ are effective, respectively. Despite the weakest parameter, it is expected that the
Optimum levels obtained from parameters

TABLE V and optimal values in these levels.

\begin{tabular}{c|c|c|c|c}
\hline \hline \multicolumn{2}{c|}{ Parameters } & $\mathrm{A}$ & $\mathrm{B}$ & $\mathrm{C}$ \\
\hline \multirow{2}{*}{ comp. strength } & opt. level & $4 \mathrm{a}$ & $4 \mathrm{~b}$ & $2 \mathrm{c}$ \\
& opt. value & - & 225 & $1 \mathrm{P}: 2 \mathrm{BA}: 1 \mathrm{RA}$ \\
\hline \multirow{2}{*}{ flex. strength } & opt. level & $4 \mathrm{a}$ & $1 \mathrm{c}$ & $1 \mathrm{~b}$ \\
& opt. value & - & 150 & $2 \mathrm{P}: 1 \mathrm{BA}: 1 \mathrm{RA}$ \\
\hline \multirow{2}{*}{ decr. of com. str. } & opt. level & $4 \mathrm{a}$ & $1 \mathrm{~b}$ & $1 \mathrm{c}$ \\
& opt. value & - & 150 & $2 \mathrm{P}: 1 \mathrm{BA}: 1 \mathrm{RA}$ \\
\hline \multirow{2}{*}{ dry unit weigth } & opt. level & $3 \mathrm{~b}$ & $3 \mathrm{c}$ & $1 \mathrm{a}$ \\
& opt. value & $\mathrm{RA}$ & 200 & $2 \mathrm{P}: 1 \mathrm{BA}: 1 \mathrm{RA}$ \\
\hline \multirow{2}{*}{ water absorption } & opt. level & $1 \mathrm{~b}$ & $4 \mathrm{c}$ & $3 \mathrm{a}$ \\
& opt. value & $\mathrm{P}$ & 225 & $1 \mathrm{P}: 1 \mathrm{BA}: 2 \mathrm{RA}$ \\
\hline \multirow{2}{*}{ capillarity } & opt. level & $2 \mathrm{a}$ & $2 \mathrm{c}$ & $3 \mathrm{~b}$ \\
& opt. value & $\mathrm{BA}$ & 175 & $1 \mathrm{P}: 1 \mathrm{BA}: 2 \mathrm{RA}$ \\
\hline \multirow{2}{*}{ thermal conduct. } & opt. level & $4 \mathrm{a}$ & $1 \mathrm{c}$ & $4 \mathrm{~b}$ \\
& opt. value & - & 150 & $1 \mathrm{P}: 1 \mathrm{BA}: 1 \mathrm{RA}$ \\
\hline \multirow{2}{*}{ cost } & opt. level & $4 \mathrm{c}$ & $1 \mathrm{~b}$ & $2 \mathrm{a}$ \\
& opt. value & - & 150 & $1 \mathrm{P}: 2 \mathrm{BA}: 1 \mathrm{RA}$ \\
\hline \multirow{2}{*}{ general } & opt. level & $4 \mathrm{~b}$ & $4 \mathrm{c}$ & $1 \mathrm{a}$ \\
& opt. value & $\mathrm{BA}$ & 225 & $2 \mathrm{P}: 1 \mathrm{BA}: 1 \mathrm{RA}$ \\
\hline
\end{tabular}

$\mathrm{a}$ - the most effective parameter, $\mathrm{b}$ - the second effective parameter, $\mathrm{c}$ - the third effective parameter

resistance of the composite mortar to the temperature increases with the increase of the $\mathrm{P}$ ratio. In addition, keeping $\mathrm{CAC}$ at the lowest level gives better result although it is fire resistant. Less use of the CAC has resulted in an increase in the spacing, which makes the material more resistant to heat.

- Dry unit weight. As expected, the increasing use of the lightest material $\mathrm{P}$ in mortar has had the greatest 


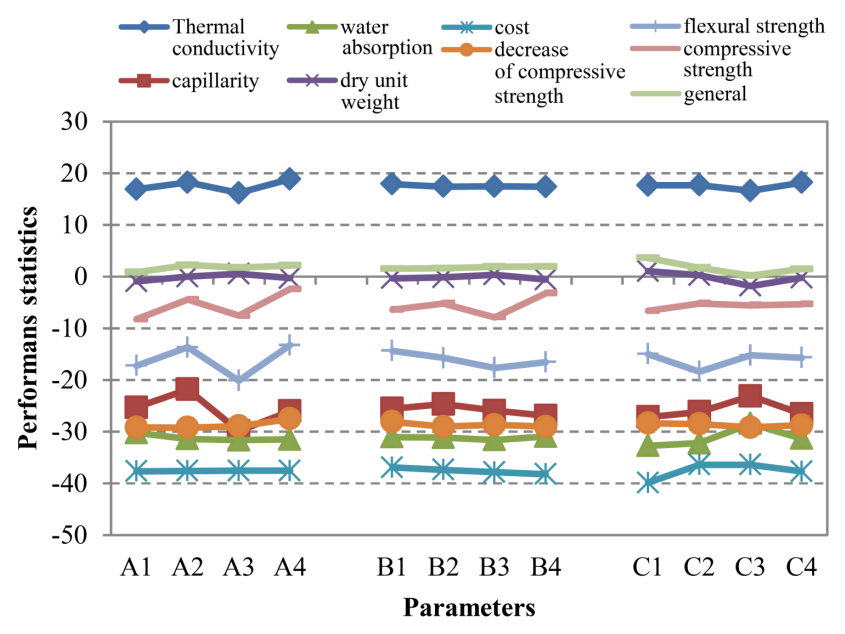

Fig. 1. Parameters and levels for $\mathrm{S} / \mathrm{N}$ ratio values of each experiment.

impact on unit weight reducing the weight. After that, IC of RA and a $200 \mathrm{~kg} / \mathrm{m}^{3}$ cement dosage are effective on dry unit weight, respectively.

- Water absorption. The P material which has much water absorption, absorbs less mixture water when IC is done, so the water absorption rate of the composite decreases. At the same time, when RA having the least water absorption potential is used more than the other aggregates, the water absorption is decreased in the mortar and this is the most effective parameter. CAC reduced water absorption as it filled more voids at the highest dosage $\left(225 \mathrm{~kg} / \mathrm{m}^{3}\right)$.

- Capillarity. The effect of the IC material in the capillary is very high and a lower capillarity value is achieved with BA. The second most effective parameter is the aggregates ratio, the best result is provided by the higher amount of RA absorbing less water. The lower amount of cement reduces the amount of capillary cracks by the formation of lower heat during the reaction.

- Thermal conductivity. Thermal conductivity decreases at the lowest amount of CAC and without IC. This is an expected result because the material that increases the thermal conductivity the most is cement. On the other hand, the lack of IC has a positive effect on the thermal conductivity reducing the amount of water in the internal micropores and it is the most effective parameter. The increase in BA here provides a better (less) thermal conductivity value. A similar finding is found in the study of Keskin and Yildirim (2016) and granulometric combination is effective [9].

- Cost. In the cost analysis, the aggregate ratio is the most effective parameter and the combination of high rate of free available RA in the mortar is successful. Here $\mathrm{P}$ is the most expensive of all materials. Cement dosage is successful in the lowest amount of cement dosage, $150 \mathrm{~kg} / \mathrm{m}^{3}$ bacause cement is an other expansive material in this composite. In addition, there is no IC effect.
- General. Aggregates ratio are the most effective and a high $\mathrm{P}$ ratio gives the most significant results. In addition, it is concluded that BA as IC material and highest dosage in the mortar of cement gives the best results.

\section{Conclusion}

Series of 16 specimens was subjected to the experiments. The results obtained for 4 levels of 3 parameters according to Taguchi method can be summarized as follows:

1. it has been found that IC does not have enough positive effect on mortars. It is thought that the cement type choice is quite effective. The process of obtaining the strength for CAC is fairly rapid. It is likely that water has had a negative effect rather than positive. It is thought that the IC water should have increased the amount of the mixing water. However, among these aggregates, BA, which on average absorb only $32.4 \%$ of the water, as compared to $\mathrm{P}$ and RA, should have had a better effect in the IC. As a matter of fact, it is the type of curing that gives the best result;

2. the increase in the amount of CAC has a positive effect because cement dosage in the mortars is kept low. Therefore, the increase in CAC is thought to have a positive effect in many experiments;

3. aggregate materials ratio, an important parameter, indicates that the materials used influence experimental performance in the direction of their own properties. As an example, it can be shown that the increase in the rate of $\mathrm{RA}$, which absorbs less water, reduces water absorption and capillarity, or the increase in $\mathrm{P}$, which is more resistant to temperature in the aggregate, reduces the decrease in strength at high temperatures. The high temperature performance of perlite and the use of CAC makes it possible to produce mortars up to $900^{\circ} \mathrm{C}$. In addition, the presence of materials such as perlite and $\mathrm{BA}$ abolishes the need to use more CAC for increase of fire endurance.

In this study, CAC has a negative effect on IC but a positive effect on temperature durability due to the fact that it is a special type of cement. In addition, the amount and type of cement, admixtures, and pozzolana can be investigated. The aggregate materials used can be replaced or added with light materials such as pumice aggregates, which are highly preferred in the market.

\section{Acknowledgments}

The authors are grateful to "Kocaeli University Scientific Researches Project Organization" for supporting the study with a project (BAP-2015/24). 


\section{References}

[1] V. Corinaldesi, J. Donnini, A. Nardinocchi, Con. Build. Mat. 94, 337 (2015).

[2] S. Aydın, Fire Saf. J. 43, 610 (2008).

[3] S.T. Yildirim, E. Kiraz, Cement Wapno Beton 18, 169 (2013), (in Polish).

[4] M. Lanzo'n, P. A. Garcı'a-Ruiz, Con. Build. Mat. 22, 1798 (2008).

[5] R. Demirboğa, R. Gül, Cement Conc. Res. 33, 723 (2003).

[6] R. Demirboğa, I. Örüng, R. Gül, Cement Conc. Res. 31, 1672 (2001).

[7] O. Sengül, S. Azizi, F. Karaosmanoglu, M.A. Tasdemir, En. Build. 43, 671 (2011).

[8] W. Zhang, W. Dai, X. Li, Heat Treat. 3, 9 (2011).
[9] F. Ş. Keskin, S.T. Yildirim, El-Cez. J. Sci. Eng. 3, 91 (2016) (in Turkish).

[10] Ö. Ölmez, M.Sc. Thesis, Hacettepe Univ., Nat. Appl. Sci. Inst., İstanbul 2010 (in Turkish).

[11] E. Canıylmaz, M.Sc Thesis, Gazi Univ., Nat. Appl. Sci. Inst., Ankara 2001 (in Turkish).

[12] İ. Türkmen, R.Gül, C. Çelik, Build. Env. 43, 1127 (2008).

[13] EN 1015-18, Methods of test mortar for masonry Part 18: Determination of water absorption coefficient due to capillary action of hardened mortar, European Committee for Standardization, 2002.

[14] EN 12664, Determination of thermal resistance by means of guarded hot plate and heat flow meter methods, European Committee for Standardization, 2002. 